\title{
Subungual amelanotic melanoma of the hallux: Review of the literature with a case report
}

\author{
Ga-Rankuwa, Pretoria, South Africa \\ NP Saragas MBBCh(Wits), FCS(SA)Ortho, MMed(Ortho Surg)(Wits) \\ University of the Witwatersrand, Johannesburg, South Africa \\ PNF Ferrao MBChB(Pret), FCS(SA)Ortho \\ University of the Witwatersrand, Johannesburg, South Africa \\ A Strydom MBBCh(Wits), FCS(SA)Ortho, MMed(Ortho Surg)(Wits) \\ Corresponding author: \\ Dr MJ Tladi \\ Department of Orthopaedics \\ Sefako Makgatho Health Science University \\ PO Box 25 \\ 0204 Medunsa \\ Tel: 0125214049 \\ Fax: 0125214284 \\ Email: mphojohn@webmail.co.za
}

MJ Tladi MBChB(UL Medunsa Campus), FCS (SA)Ortho, MMed(Orth Surg)(SMU)

Dr George Mukhari Academic Hospital, Ga-Rankuwa, Pretoria and Sefako Makgatho Health Science University,

Netcare Linksfield Orthopaedic Sports \& Rehabilitation Centre (Clinic), Johannesburg and Orthopaedic Department,

Netcare Linksfield Orthopaedic Sports \& Rehabilitation Centre (Clinic), Johannesburg and Orthopaedic Department,

Orthopaedic Department, University of the Witwatersrand, Johannesburg, South Africa

\begin{abstract}
Subungual melanoma of the hallux is a rare malignancy occurring mainly in elderly black Africans and Asians. It is often misdiagnosed as a benign lesion. We present a review of the English literature and report on a case of an 80-year-old Caucasian female patient who presented with a rare subungual amelanotic malignant melanoma of the hallux that was initially misdiagnosed as an ingrown toenail. Due to lack of pigmentation, amelanotic melanoma poses a huge dilemma in diagnosis. Upon comparing this case with the current literature, we propose that unlike most acral subungual melanomas, subungual amelanotic melanoma occurs mainly in elderly Caucasian females.
\end{abstract}

Level of study: IV case series

Key words: subungual melanoma, melanoma, amelanotic, acral lentiginous melanoma

http:/ / dx.doi.org/10.17159/2309-8309/2017/v16n2a5

\section{Introduction}

Subungual melanoma was first fully described in 1886 by Sir Hutchinson, ${ }^{1}$ yet in the 21 st century this condition is still misdiagnosed resulting in a high morbidity and mortality. The famous reggae singer, Bob Marley, succumbed to an aggressive subungual malignant melanoma of the hallux at the age of 36 years.,3 Lack of pigmentation in amelanotic subungual melanoma further complicates an already difficult diagnosis. ${ }^{4-6}$

\section{Case report}

\section{Clinical history}

We present an 80-year-old Caucasian female who presented with an 18-month history of a lesion under her right hallux toenail. She consulted a podiatrist who initially diagnosed it as an ingrown toenail and managed it accordingly. The lesion did not resolve and she continued to have episodes of bleeding with closed shoes. 


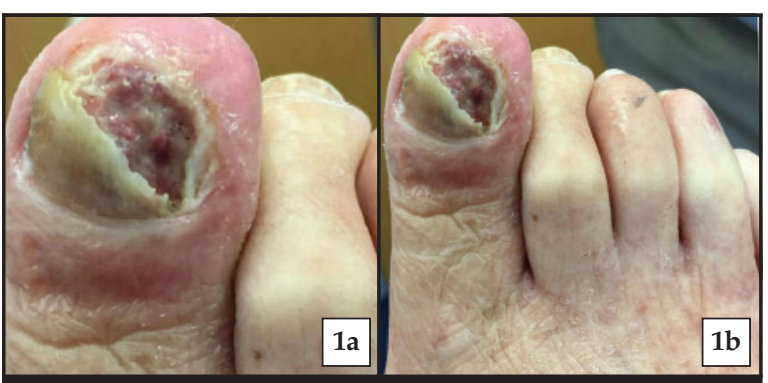

Figure 1. A granulomatous lesion of the hallux

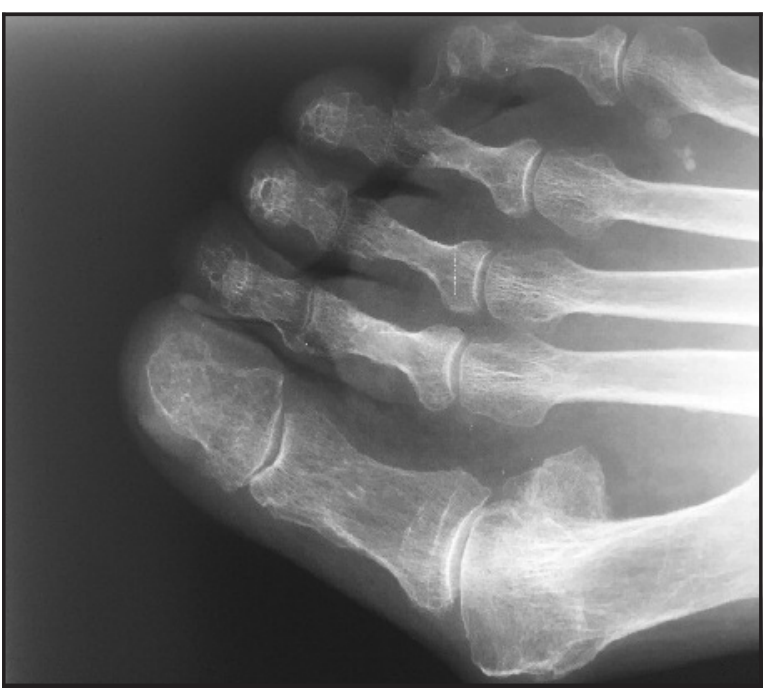

Figure 2. X-ray showing no bony involvement

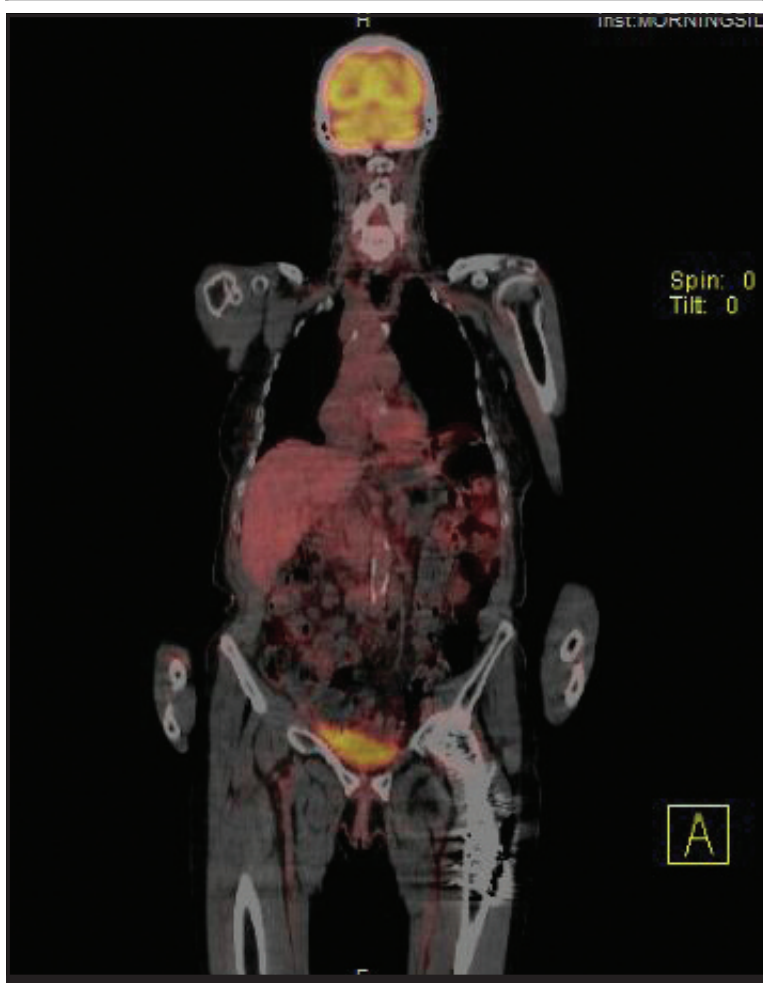

Figure 3. PET CT scan with no evidence of metastasis
The patient was referred to a dermatologist who performed a biopsy. The diagnosis of an amelanotic melanoma was made upon histology. There was no history of previous trauma to the nail or positive family history of melanoma $(5 \%-10 \%$ reported incidence of a positive family history). ${ }^{7}$

\section{Examination}

Examination revealed a generally well elderly Caucasian female. A granulomatous type lesion, measuring $2 \mathrm{~cm}$ by $1.5 \mathrm{~cm}$, was present overlying the nail bed of the right hallux (Figures $1 a$ and $1 b$ ). The lesion was tender to palpation. No ipsilateral inguinal lymph nodes were palpable and the foot was neurovascularly intact.

\section{Special investigations}

No bony involvement was evident on plain radiographs (Figure 2). A PET CT scan (Figure 3) showed no metastases.

\section{Management}

Once the case was discussed with an oncologist, informed consent was obtained from the patient to perform a partial amputation of the hallux. The hallux was amputated at the level of the mid-shaft of the proximal phalanx, allowing for at least a $15 \mathrm{~mm}$ clear margin from the tumour edge (Figures $4 a$ and $4 b$ ). The histology report once again confirmed the amelanotic melanoma, stage IIb (Figure 5), with $20 \mathrm{~mm}$ clear margins. The patient was referred to the oncology unit for further treatment as required.
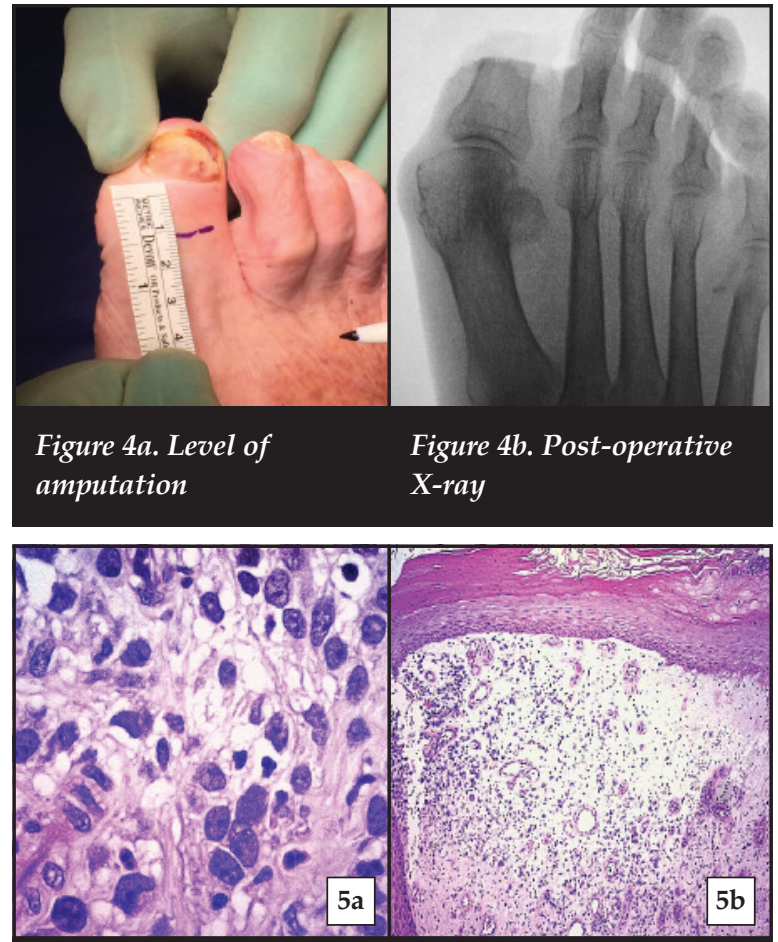

Figure 5. Histology showing amelanotic melanoma 


\section{Discussion}

Pigmentation of the toenails can be due to benign, systemic disease manifestation or malignant conditions, with melanoma being one of the rare malignancies (3.2\% of foot and ankle tumours). ${ }^{8,9}$ Generally there are four types of melanoma, with acral melanoma affecting the hands and feet. This usually occurs in black African and Asian populations contrary to the other types which are more common in fair-skinned populations., ${ }^{7,9}$ Delayed diagnosis of subungual melanoma is largely due to misdiagnosing the lesion as being benign (Table I).,8-12 Table II shows all case reports of subungual amelanotic melanoma affecting the hallux, all of which had a delay in the diagnosis. Only five case reports were identified after an extensive search of the English literature.

Table I: Common benign conditions resembling subungual melanoma

\begin{tabular}{|l|l|}
\hline Subungual haematoma & Subungual exostosis \\
Paronychia & Mucous cyst \\
Ingrown toenail & Subungual fibroma \\
Granuloma & Keratoacanthoma \\
Ethnic pigmentation & Dermatofibroma \\
Onychomycosis nigricans & Wart \\
Glomus tumour & \\
Benign naevus & \\
\hline
\end{tabular}

The incidence of subungual melanoma is high in black Africans and Asians between the ages of 50 to 70 years. Males and females are equally affected..$^{4,78}$ Our case, however, was in an 80-year-old Caucasian female. Upon reviewing the literature reporting on subungual amelanotic melanoma of the hallux, all patients were Caucasian, with $60 \%$ being female. We thus propose that subungual amelanotic melanoma actually has a higher incidence in Caucasian females. Symptoms in most cases are vague and the lesion resembles other conditions. The $\mathrm{ABCDEF}$ rule was described by Levit et al. to reduce misdiagnosing subungual melanomas and improve early detection (Table III). ${ }^{16}$ Hutchinson's sign describes a black discoloration of the proximal nail fold which is suggestive of subungual melanoma. This sign has inherent flaws as it has no role in amelanotic melanoma due to absence of pigmentation, as was seen in our patient. Hutchinson's sign can also be associated with Laugier-Hunziker syndrome, ethnic pigmentation, infections or the use of certain medications. When present, however, it is indicative of a poor prognosis. ${ }^{8,16}$

Management of subungual melanoma of the hallux is usually amputation of the digit, which can cause functional and emotional problems, such as in the case of Bob Marley who refused amputation due to religious reasons and only agreed to local excision of the tumour. ${ }^{2,4,17}$

Table II: Literature case reports of hallux subungual amelanotic melanoma

\begin{tabular}{|c|c|c|c|c|c|}
\hline Race & $\begin{array}{c}\text { Age } \\
\text { (years) }\end{array}$ & Sex & Initial diagnosis & Author & $\begin{array}{c}\text { Surgical } \\
\text { management }\end{array}$ \\
\hline Caucasian & 71 & female & in-growing toenail & Cahill et al..$^{11}$ & amputation \\
\hline Caucasian & 35 & female & in-growing toenail & Winslet et al. ${ }^{13}$ & amputation \\
\hline Caucasian & 31 & male & mass & Gosselink et al. ${ }^{6}$ & amputation \\
\hline Caucasian & 61 & male & $\begin{array}{l}\text { pyogenic granuloma, squamous cell carcinoma, } \\
\text { amelanotic malignant melanoma, deep fungal infection, } \\
\text { verruca or cutaneous leishmaniasis }\end{array}$ & Arican et al..$^{14}$ & amputation \\
\hline Caucasian & 72 & female & fungal infection & Koch et al. ${ }^{15}$ & amputation \\
\hline
\end{tabular}

Table III: Steps to follow when suspecting subungual melanoma

A Age: Range 20-90 y, peak 5th-7th decades

Race: African-American, Native American, Asian

Band (nail band): pigment (Brown-Black)

B Breadth $(\geq 3 \mathrm{~mm})$

Border (irregular/blurred)

Change: Rapid increase in size/growth rate of nail band

C Lack of Change: Failure of nail dystrophy to improve despite adequate treatment

Digit involved: Thumb $>$ hallux $>$ index finger

D Single digit $>$ multiple digits Dominant hand

E Extension: Extension of pigment to involve proximal or lateral nail fold (Hutchinson's sign) or free edge of nail plate

Family or personal history: Of previous melanoma or dysplastic naevus syndrome
This ultimately resulted in metastasis and his demise. As the diagnosis is often delayed with resultant local invasion, amputation is the recommended management. ${ }^{17}$

The tissue must be sent for histology and the report should include: histological type, presence of ulceration, presence of infiltrative lymphocytes, regression, microsatellite lesions, margins, micro-staging (tumour thickness according to Breslow and level of invasion according to Clark) which are helpful with final staging. ${ }^{7,10}$ Melanoma is staged according to the American Joint Committee on Cancer (AJCC). ${ }^{7}$ A sentinel lymph node (SLN) biopsy is recommended for melanomas stage $1 \mathrm{~b}$ and above. ${ }^{7}$ Recurrence of foot melanoma is $37 \%$ at approximately 3 years and survival rate after recurrence is shorter than 41 months. ${ }^{18}$ Prognosis of subungual melanoma in general is poor. The 5-year survival rate of subungual melanoma of the toe is $40 \%$ as compared to $72 \%$ in the finger. ${ }^{17}$ 
The 5-year survival rate for melanoma in general is $74.3 \%$ in the foot and $85.2 \%$ in the leg. ${ }^{18}$ The survival rate is directly related to the staging by the AJCC.

\section{Conclusion}

Subungual melanoma is rare, especially in the Caucasian population. However, the incidence of subungual amelanotic melanoma has only been reported in Caucasians, contrary to other subungual melanomas which occur mainly in black Africans and Asians. There is also a predilection for the female gender. We thus propose that subungual amelanotic melanoma occurs mainly in elderly Caucasian females. The diagnosis is often delayed, as it can mimic a variety of hallux nail conditions. Due to lack of pigmentation, amelanotic melanoma poses a huge dilemma in diagnosis. A high index of suspicion is thus imperative. The use of the ABCDEF rule can help in increasing awareness and reducing the delay in diagnosing subungual amelanotic melanoma. An incisional biopsy should be performed early. Once histological confirmation is made, amputation is the treatment of choice and the patient should be referred to an oncology unit for further management according to the AJCC staging.

\section{Acknowledgements}

The authors wish to acknowledge Dr B Wium for providing the histological pictures used in this manuscript.

\section{Compliance with ethics guidelines}

\section{Conflict of interest statement}

The authors declare they have no conflict of interests in writing this article. No financial support was received for this study. The content of the article is the original work of the authors.

\section{References}

1. Hutchinson J. Melanosis often not black: melanotic whitlow. Br Med J 1886;1:491.

2. Bob Marley explained. http:/ / everything.explained.today /Bob_Marley/ [accessed on 16 June 2016].

3. Menon S. An incidental finding. Ifponline.com 2013;62(11):655-59.
4. Briggs J. Subungual malignant melanoma: a review article. British Journal of Plastic Surgery 1985;38:174-76.

5. Mark D, Yoong S, Reid J, Khan K. Amelanotic melanoma presenting as a neuropathic ulcer in a non-diabetic patient. J Med Cases 2012;2:146-48.

6. Gosselink C, Sindone J, Meadows B, Mohammadi A, Rosa M. Amelanotic subungual melanoma: a case report. Journal of Foot \& Ankle Surgery 2009;48(2):220-24.

7. de Braud F, Khayat D, Kroon B, Valdagni R, Bruzzi P, Cascinelli N. Malignant melanoma. Critical Reviews in Oncology/Haematology 2003;47:53-63.

8. Patel G, Ragi G, Krysicki J, Schwatz R. Subungual melanoma: a deceptive disorder. Acta Dermatovenerol Croat 2008;16(4):236-42.

9. Chou L, Ho Y, Malawer M. Tumors of the foot and ankle: experience with 153 cases. Foot and Ankle International 2009;30(9):836-41.

10. Dunki-Jacobs E, Callender G, McMaster K. Current management of melanoma. Current Problems in Surgery 2013;50:351-82.

11. Cahill S, Cryer J, Otter S, Ramesar K. An amelanotic maligant melanoma masquerading as a hypergranulation tissue. Foot and Ankle Surgery 2009;15:158-60.

12. Fortin P, Friberg A, Rees R, Sondak V, Johnson T. Malignant melanoma of the foot and ankle. The Journal of Bone and Joint Surgery 1995;77-A(9):1396-403.

13. Winslet M, Tejan J. Subungual amelanotic melanoma: a diagnostic pitfall. Postgrad Med J 1990;66:200-202.

14. Arican O, Sasmaz S, Coban Y, Ciralik H. Subungual amelanotic malignant melanoma. Saudi Med J 2005;27(2):247-49.

15. Koch S, Lange J. Amelanotic melanoma: the greater maquerader. J Am Acad Dermatol 2000;42:731-34.

16. Levit E, Kagen M, Scher R, Grossman M, Altman E. ABC rule for clinical detection of subungual melanoma. J Am Acad Dermatol 2000;42:269-74.

17. Cohen T, Busam K, Patel A, Brady M. Subungual melanoma: management considerations. American Journal of Surgery 2008;195:244-48.

18. Talley L, Soong S, Harrison R, McCarthy W, Urist M, Balch C. Clinical outcomes of localised melanoma of the foot: a case control study. J Clin Epidemiol 1998;51(10):853-57.

This article is also available online on the SAOA website (www.saoa.org.za) and the SciELO website (www.scielo.org.za). Follow the directions on the Contents page of this journal to access it. 